\title{
Mid-Term Outcome after Tricuspid Valve Replacement
}

Yanmei Cheng1', MD, PhD; Shaoyan Mo², MD; Keke Wang ${ }^{3}$, MD; Rui Fann ${ }^{4}$ MD; Yunqi Liu ${ }^{3}$, MD, PhD; Si Li ${ }^{1}, \mathrm{MD}, \mathrm{Xi}$

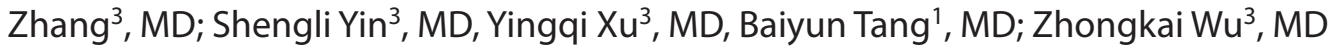

DOI: $10.21470 / 1678-9741-2019-0215$

\begin{abstract}
Objective: To evaluate the mid-term survival rate after tricuspid valve replacement (TVR).

Methods: We retrospectively studied 110 consecutive patients who underwent TVR from January 2007 to November 2017. A survival analysis was performed with the Kaplan-Meier method and the log-rank test.

Results: The median survival was 65.81 months. Mean age was 50 (range 39 to 59 ) years. Forty-eight patients (43.6\%) were male, and 62 patients $(56.4 \%)$ were female. Most of the patients (78.5\%) were categorized into the New York Heart Association (NYHA) functional classes III/IV. Seventy-two patients (65.5\%) had isolated TVR. Six-three patients $(57.3 \%)$ had previously undergone heart surgery. The Kaplan-Meier survival rates at one year, three years, and five years were $59.0 \% \pm 5 \%, 52.0 \% \pm 6 \%$, and
\end{abstract}

$48.0 \% \pm 6 \%$, respectively. A Cox regression analysis demonstrated that the risk factors for mid-term mortality were advanced NYHA class (hazard ratio [HR] 2.430, 95\% confidence interval [CI] 1.0995.375, $P=0.028)$, need for continuous renal replacement therapy (CRRT) treatment (HR 3.121, 95\% Cl 1.610-6.050, P=0.001), and need for intra-aortic balloon pump (IABP) treatment (HR 3.356, 95\% Cl 1.072-10.504, $P=0.038$ ).

Conclusion: In TVR, impaired cardiac function before the operation and a need for CRRT or IABP treatment after the operation is independently associated with increased mid-term mortality.

Keywords: Cardiac Surgical Procedures. Tricuspid Valve. Risk factors. Intra-Aortic Balloon Pumping. Confidence Intervals. Survival Rate.

\begin{tabular}{llll}
\hline \multicolumn{2}{l}{ Abbreviations, acronyms \& symbols } & & \\
\hline ASDR & = Atrial septal defect repair & NYHA & $=$ New York Heart Association \\
AVR & = Aortic valve replacement & PADR & $=$ Patent ductus arteriosus repair \\
AVS & = Atrioventricular shunt & PBMV & $=$ Percutaneous balloon mitral valvuloplasty \\
CI & $=$ Confidence interval & PBTV & $=$ Percutaneous balloon tricuspid valvuloplasty \\
CRRT & $=$ Continuous renal replacement therapy & RV & $=$ Right ventricular or right ventricle \\
DVR & $=$ Double valve replacement & RVSP & $=$ Right ventricular systolic pressure \\
eGFR & $=$ Estimated glomerular filtration rate & TAP & $=$ Tricuspid annuloplasty \\
EuroSCORE & $=$ European System for Cardiac Operative Risk Evaluation & TR & $=$ Tricuspid regurgitation \\
HR & $=$ Hazard ratio & TV & $=$ Tricuspid valve \\
IABP & $=$ Intra-aortic balloon pump & TVR & $=$ Tricuspid valve replacement \\
MVR & $=$ Mitral valve replacement & VSDR & $=$ Ventricular septal defect repair \\
\hline
\end{tabular}

'Department of Cardiothoracic Surgery ICU, The First Affiliated Hospital of Sun Yatsen University, Guangzhou, People's Republic of China.

${ }^{2}$ Department of Cardiopulmonary Bypass, The First Affiliated Hospital of Sun Yat-sen University, Guangzhou, People's Republic of China.

${ }^{3}$ Department of Cardiac Surgery, The First Affiliated Hospital of Sun Yat-sen University, Guangzhou, People's Republic of China.

${ }^{4}$ Department of Echocardiography, The First Affiliated Hospital of Sun Yat-sen University, Guangzhou, People's Republic of China.

This study was carried out at the Department of Cardiothoracic Surgery ICU, The First Affiliated Hospital of Sun Yat-sen University, Guangzhou, People's Republic of China.
Correspondence Address:

Baiyun Tang

iD https://orcid.org/0000-0001-7025-6915

Department of Cardiothoracic Surgery ICU, The First Affiliated Hospital of Sun Yat-sen University

58 Zhongshan Rd. No.2, Guangzhou, People's Republic of China - Zip Code: 510080 E-mail: tangbaiyun611@163.com

Zhongkai Wu

(iD) https://orcid.org/0000-0003-1184-1182

Department of Cardiac Surgery, The First Affiliated Hospital of Sun Yat-sen University 58 Zhongshan Rd. No.2, Guangzhou, People's Republic of China - Zip Code: 510080 E-mail:wuzhk@mail.sysu.edu.cn 


\section{INTRODUCTION}

Symptoms of tricuspid regurgitation (TR) are often nonspecific. However, surgical intervention for severe TR is only indicated in symptomatic patients ${ }^{[1]}$, and significant symptoms include signs of severe comorbidities. Therefore, patients referring for tricuspid valve (TV) surgery were often at a late stage, when right ventricular (RV) dysfunction has already occurred and TV repair has failed or is impossible, often risking a high mortality rate ${ }^{[1]}$.

In light of the high mortality rate in tricuspid valve replacement (TVR), an appropriate patient selection is crucially important for good clinical outcomes; however, the objective criteria are currently unavailable. Therefore, efforts have been made to determine predictors of clinical outcomes to perform a TVR procedure. The aim of our study was to identify the midterm mortality risk factors for TVR, which might help in patient selection, yielding a satisfactory clinical outcome.

\section{METHODS}

\section{Patient Selection}

We retrospectively analyzed 110 patients who underwent TVR over a 10-year period, from January 2007 to November 2017. Ethics approval was obtained from the Medical Ethics Committee of the First Affiliated Hospital of Sun Yat-sen University. We included patients who underwent TVR either as an isolated procedure or in combination with other procedures. Late followup data were obtained from hospital records and from telephone contact with patients. The requirement for individual patient consent was waived because of the retrospective study design.

\section{Data Collection}

Characteristics including sex, age, etiology, weight, height, diabetes mellitus, hypertension, coronary heart disease, atrial fibrillation, and New York Heart Association (NYHA) functional class were retrieved from hospital records. Laboratory parameters including hemoglobin, serum concentrations of bilirubin, alanine aminotransferase, creatinine, and blood urea nitrogen were collected. The estimated glomerular filtration rate (eGFR) was calculated using the Modification of Diet in Renal Disease equation: $\operatorname{eGFR}\left(\mathrm{mL} / \mathrm{min} / 1.73 \mathrm{~m}^{2}\right)=175 \times$ (serum creatinine)-1.234 $\times$ (age)-0.179 $\times(0.79$, if female). Operative variables including prosthesis type, aortic cross-clamp and cardiopulmonary bypass times, and postoperative variables requirements for intraaortic balloon pump (IABP) and continuous renal replacement therapy (CRRT) were collected. The European System for Cardiac Operative Risk Evaluation (EuroSCORE) II was calculated (http:// www.euroscore.org/calc.html).

Two-dimensional transthoracic echocardiographic parameters were collected. Left ventricular ejection fraction was measured as guideline. Right atrial dimensions were estimated at end-diastole from an apical four-chamber view. Both right atrial length (referred to as the major dimension) and right atrial diameter (known as the minor dimension) at end-diastole were collected. The severity of TR was semiquantitatively graded as none, mild, moderate, moderately severe, severe, and extremely severe by quantifying TR velocity using color-flow Doppler from an apical view. The right ventricular systolic pressure (RVSP) was estimated based on continuous-wave Doppler measurements of TR jet velocity by using the modified Bernoulli equation ${ }^{[2]}$.

\section{Statistical Analysis}

The categorical variables, which are presented as frequencies and percentages, were compared by using the $x^{2}$ test or Fisher's exact test. The continuous variables, which are expressed as means \pm standard deviation or medians with ranges, were compared by using Student's unpaired t-test or Mann-Whitney $U$ test. Analyses of survival were performed with the Kaplan-Meier method and the log-rank test. The overall mortality after triple valve operation was assessed by using the Cox proportional hazard model and was expressed as a hazard ratio (HR) with a 95\% confidence interval (Cl). Statistical significance was established with a $P$-value $<0.05$.

\section{RESULTS}

\section{Baseline Patient Characteristics}

Table 1 summarizes the patients' baseline demographic and clinical data. The mean patient age was 50 (range 39 to 59) years. Forty-eight patients (43.6\%) were male, and 62 patients (56.4\%) were female. The primary etiology for operative intervention was TV insufficiency caused by rheumatic heart disease in 41.8\% (46/110) of the patients, followed by TV endocarditis in $21.8 \%$ (24/110) of the patients, degenerative valve disease in $20.9 \%$ (23/110) of the patients, and congenital heart disease in $15.5 \%(17 / 110)$ of the patients, with Ebstein's anomaly in nine patients. The preoperative cardiac functions of the patients were classified as being NYHA functional class II (20.9\%), III (71.8\%), and IV (7.3\%). Sixty-three (57.3\%) patients had undergone previous cardiac operations. Chronic atrial fibrillation was present in 59 (53.6\%) patients.

Isolated TVR was performed in 72 (65.5\%) patients. TVR concomitant procedures were performed in 28 (25.5\%) patients. The mean cardiopulmonary bypass time was 130 minutes (range 80 to 182 minutes). Sixty-two (56.4\%) procedures were performed with aortic cross-clamping. Bioprosthetic valves were implanted in 74 (67.3\%) patients and mechanical valves in 36 (32.7\%) patients.

\section{Echocardiographic Parameters}

The baseline echocardiographic parameters were assessed by qualitative inspection of the 2D images. The left ventricular ejection fraction was $63.06 \% \pm 9.62 \%$. Left ventricular enddiastolic diameter was $47.5 \mathrm{~mm}$ (range 41 to $52 \mathrm{~mm}$ ). RV diameter was $46.63 \pm 14.93 \mathrm{~mm}$. Right atrial diameter was $69.5 \mathrm{~mm}$ (range 58 to $83 \mathrm{~mm}$ ) and left atrial length was $50 \mathrm{~mm}$ (range 42 to 68 $\mathrm{mm}$ ). The left atrial diameter was $47.5 \mathrm{~mm}$ (range 35 to $54 \mathrm{~mm}$ ). The RVSP was $41 \mathrm{mmHg}$ (range 32 to $53 \mathrm{mmHg}$ ). There were only $14(12.5 \%)$ patients with equal to or more severe than moderate mitral regurgitation. The majority $(72.7 \%, 80 / 110)$ of the patients had severe or more than severe TR.

Sixty-three (57.3\%) patients had mitral valve replacement due to mitral valve disease, regurgitation, or stenosis. Eighteen (16.4\%) patients had atrioventricular shunt. The detailed data of these two groups were presented in Table 2. 
Table 1. Summary of the patients' baseline demographic profiles.

\section{Characteristics}

Age, years

Male, n (\%)

Heart rate, bpm

Systolic blood pressure, $\mathrm{mmHg}$

Diastolic blood pressure, $\mathrm{mmHg}$

Body mass index, $\mathrm{kg} / \mathrm{m}^{2}$

Isolated TVR, n (\%)

Previous heart disease, $\mathrm{n}(\%)$

NYHA, n (\%)

Coronary artery disease, $\mathrm{n}(\%)$

Hypertension, n (\%)

Diabetes mellitus, n (\%)

Atrial fibrillation, $\mathrm{n}(\%)$

Cardiopulmonary bypass time, min

Aortic cross-clamping, n (\%)

Prosthetic valve, $\mathrm{n}$ (\%)

Bioprosthesis

Mechanical prosthesis

\section{Laboratory examinations}

Hemoglobin, g/L

Alanine aminotransferase, U/L

Bilirubin, umol/L

Blood urea nitrogen, $\mathrm{mmol} / \mathrm{L}$

Creatinine, $\mu \mathrm{mol} / \mathrm{L}$

eGFR, $\mathrm{ml} / \mathrm{min} / 1.73 \mathrm{~m}^{2}$

Right atrial diameter, $\mathrm{mm}$

Right atrial length, $\mathrm{mm}$

Left atrium, $\mathrm{mm}$

Left ventricular end-diastolic diameter, $\mathrm{mm}$

Left ventricular ejection fraction $\leq 55 \%$

Right ventricular, $\mathrm{mm}$

Mitral regurgitation $\geq$ moderate, $\mathrm{n}(\%)$

Mitral stenosis $\geq$ moderate, $\mathrm{n}(\%)$

Tricuspid regurgitation $\geq$ severe, $\mathrm{n}(\%)$

RVSP, mmHg

CRRT, n (\%)

IABP, n (\%)

EurOSCORE II (\%)
Etiology for intervention, n (\%)

\section{All $(n=110)$}

$50(39,59)$

48 (43.6)

$81(75,95)$

$119(110,131)$

$72(64,80)$

$20.96(19.23,23.41)$

$72(65.5)$

$24(21.8)$

46 (41.8)

$23(20.9)$

$17(15.5)$

63 (57.3)

23 (20.9)

$79(71.8)$

$8(7.3)$

$4(3.6)$

$11(10)$

$5(4.5)$

$59(53.6)$

$130(80,182)$

62 (56.4)

74 (67.3)

$36(32.7)$

\begin{tabular}{c}
$124.5(103,138)$ \\
\hline $26.39 \pm 23.91$ \\
$23.69 \pm 15.64$ \\
$6.54 \pm 4.82$ \\
$77.25 \pm 32.55$ \\
$110.17 \pm 55.14$ \\
$69.5(58,83)$ \\
\hline $50(42,68)$ \\
\hline $47.5(35,54)$ \\
\hline $47.5(41,52)$ \\
$63.06 \pm 9.62$ \\
\hline $46.63 \pm 14.93$ \\
$14(12.7)$ \\
\hline $15(13.6)$ \\
$80(72.7)$ \\
$41(32,53)$ \\
$27(24.5)$ \\
$5(4.5)$ \\
\hline $3.25(2.42,4.61)$
\end{tabular}

CRRT=continuous renal replacement therapy; eGFR=estimated glomerular filtration rate; EuroSCORE=European System for Cardiac Operative Risk Evaluation; IABP=intra-aortic balloon pump; NYHA=New York Heart Association; RVSP=right ventricular systolic pressure; TVR=tricuspid valve replacement 
Table 2. Patients with atrioventricular shunt (AVS) and mitral valve disease.

\begin{tabular}{|c|c|c|c|c|c|c|c|}
\hline & \multicolumn{3}{|c|}{$\begin{array}{l}\text { Patients with AVS } \\
\quad \text { (Total } n=18 \text { ) } \\
\text { Indication for TVR }\end{array}$} & \multicolumn{4}{|c|}{$\begin{array}{c}\text { Patients with MVR procedure } \\
\text { (Total } n=66 \text { ) } \\
\text { Indication for TVR }\end{array}$} \\
\hline & $\begin{array}{c}\text { Infective } \\
\text { endocarditis } \\
(n=7)\end{array}$ & $\begin{array}{l}\text { Ebstein's } \\
\text { anomaly } \\
\quad(n=3)\end{array}$ & $\begin{array}{l}\text { Other } \\
(n=8)\end{array}$ & $\begin{array}{l}\text { Rheumatic } \\
\text { heart disease } \\
\quad(n=46)\end{array}$ & $\begin{array}{l}\text { Degenerative } \\
\text { valve disease } \\
\quad(n=15)\end{array}$ & $\begin{array}{l}\text { Congenital } \\
\text { heart disease } \\
\quad(n=3)\end{array}$ & $\begin{array}{c}\text { Infective } \\
\text { endocarditis } \\
(n=2)\end{array}$ \\
\hline \multirow{8}{*}{ Previous heart procedure } & $n=2(28.6 \%)$ & $n=1(33.3 \%)$ & $\mathrm{n}=6(75.0 \%)$ & $\mathrm{n}=38(82.6 \%)$ & $\mathrm{n}=10(66.7 \%)$ & $n=2(66.7 \%)$ & $n=1(50 \%)$ \\
\hline & $\begin{array}{l}1 \text { VSDR+ASDR+ PADR } \\
\text { with residual shunt }\end{array}$ & $1 \mathrm{TAP}+\mathrm{ASD}$ & 2 ASDR & $1 \mathrm{AVR}$ & $5 \mathrm{MVR}$ & $1 \mathrm{ASDR}$ & $1 \mathrm{MVR}+\mathrm{TAP}$ \\
\hline & $1 \mathrm{VSDR}$ & & $1 \mathrm{VSDR}$ & 13 DVR & $5 \mathrm{DVR}$ & $1 \mathrm{VSDR}+\mathrm{MVR}$ & \\
\hline & & & $1 \mathrm{TAP}+\mathrm{ASDR}$ & 1 PBMV; DVR & & & \\
\hline & & & 2 Fallot & $19 \mathrm{MVR}$ & & & \\
\hline & & & & $1 \mathrm{MVR}+\mathrm{TAP}$ & & & \\
\hline & & & & $1 \mathrm{MVR}+\mathrm{PBTV}$ & & & \\
\hline & & & & 2 PBMV & & & \\
\hline \multirow{7}{*}{ Concomitant procedure } & $\mathrm{n}=6(85.7 \%)$ & $n=2(66.7 \%)$ & $\mathrm{n}=4(50 \%)$ & $\mathrm{n}=16(34.8 \%)$ & $n=6(40 \%)$ & $n=3(100 \%)$ & $n=2(100 \%)$ \\
\hline & $1 \mathrm{ASDR}$ & 1 ASDR & $1 \mathrm{MVR}$ & $7 \mathrm{MVR}$ & $2 \mathrm{AVR}$ & $1 \mathrm{MVR}$ & $2 \mathrm{MVR}$ \\
\hline & 1 Fallot & 1 Fallot & $2 \mathrm{VSDR}$ & $1 \mathrm{MVR}+\mathrm{TAP}$ & $4 \mathrm{MVR}$ & $2 \mathrm{ASDR}+\mathrm{MVR}$ & \\
\hline & 1VSDR+ASDR+AVR & & 1 ASDR+MVR & $4 \mathrm{AVR}$ & & 3 VSDR & \\
\hline & $1 \mathrm{VSDR}$ & & & $4 \mathrm{DVR}$ & & & \\
\hline & 1ASDR+VSDR+Gleen & & & & & & \\
\hline & $1 \mathrm{AVR}$ & & & & & & \\
\hline \multirow{4}{*}{ Mitral regurgitation } & \multirow{4}{*}{ None } & \multirow{4}{*}{ None } & $n=1(12.5)$ & $\mathrm{n}=37(17.5 \%)$ & $\mathrm{n}=11(73.3 \%)$ & $\mathrm{n}=1(33.3 \%)$ & \multirow{4}{*}{$n=2(100 \%)$} \\
\hline & & & 1 Severe & 31 Mild & 7 Mild & 1 Severe & \\
\hline & & & & 3 Mediate & 2 Mediate & & \\
\hline & & & & 3 Severe & 2 Severe & & \\
\hline \multirow{4}{*}{ Mitral stenosis } & \multirow{4}{*}{ None } & \multirow{4}{*}{ None } & \multirow{4}{*}{ None } & $n=12(26.1 \%)$ & $n=1$ & \multirow{4}{*}{ None } & \multirow{4}{*}{ None } \\
\hline & & & & 1 Mild & $\begin{array}{c}1 \text { Severe (stuck } \\
\text { leaflet) }\end{array}$ & & \\
\hline & & & & 5 Mediate & & & \\
\hline & & & & 6 Severe & & & \\
\hline Right atrial length, mm & $56.43 \pm 26.27$ & $51.33 \pm 10.69$ & $60.13 \pm 17.88$ & $53.73 \pm 14.08$ & $58.00 \pm 19.75$ & $76.67 \pm 7.51$ & $31.50 \pm 0.71$ \\
\hline Right atrial diameter, mm & $58.86 \pm 19.89$ & $78.33 \pm 35.25$ & $72.88 \pm 15.61$ & $74.20 \pm 14.18$ & $78.70 \pm 18.56$ & $63.67 \pm 22.59$ & $42.5 \pm 0.71$ \\
\hline RVSP, mmHg & $65.71 \pm 38.16$ & $50.67 \pm 45.00$ & $50.25 \pm 20.6$ & $40.47 \pm 11.96$ & $44.91 \pm 15.69$ & $67.00 \pm 23.52$ & $48.50 \pm 12.02$ \\
\hline Death & $2(28.6 \%)$ & $1(33.3 \%)$ & $4(50.0 \%)$ & $21(45.7 \%)$ & $3(20.0 \%)$ & $1(33.3 \%)$ & $1(50.0 \%)$ \\
\hline
\end{tabular}

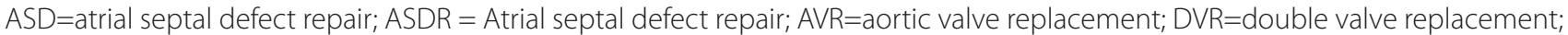
$M V R=$ mitral valve replacement; $P A D R=$ patent ductus arteriosus repair; PBMV=percutaneous balloon mitral valvuloplasty; PBTV=percutaneous balloon tricuspid valvuloplasty; TAP=tricuspid annuloplasty; TVR=tricuspid valve replacement; RVSP=right ventricular systolic pressure; VSDR=ventricular septal defect repair 


\section{Cox Regression Analysis}

At the conclusion of our study, there was a median followup time of 65.81 months. The Cox univariate analysis revealed that bilirubin $(P<0.001)$, blood urea nitrogen $(P=0.031)$, creatinine $(P=0.032)$, need for CRRT after surgery $(P<0.001)$, need for IABP after surgery $(P=0.006)$, advanced NYHA class $(P<0.001)$, right atrial diameter $(P=0.048)$, and cardiopulmonary bypass time $(P=0.026)$ were risk factors for mid-term mortality (Table 3).

In the adjusted Cox regression analysis, NYHA class (HR 2.430, 95\% Cl 1.099-5.375, $P=0.028)$, need for CRRT treatment ( $H R$ $3.121,95 \% \mathrm{Cl} 1.610-6.050, P=0.001)$, and need for IABP treatment ( HR 3.356, 95\% Cl 1.072-10.504, $P=0.038$ ) remained to be independently associated with increased late mortality (Table 3).

\section{Survival at Follow-up}

Figure 1 shows the survival curves of the significant variables in both the univariate and multivariate analysis. Table 4 displays the time-related survival rates. The overall one-year, three-year, and five-year survival rates were $58 \% \pm 5 \%, 51 \% \pm 6 \%$, and $47 \% \pm 6 \%$, respectively. The mortality rate was 100\% for patients in NYHA class IV, whereas the one-year, three-year, and five-year survival rates were $62.3 \%, 61.0 \%$, and $52.6 \%$, respectively, in NYHA class III, and the one-year, three-year, and five-year survival rates were 83.3\%, 72.5\%, and $72.5 \%$, respectively, in NYHA class $\|(P<0.001)$. Patients who needed CRRT treatment were more predisposed to death than patients who did not need CRRT treatment, with one-year, three-year, and five-year survival rates of 28\%, 22.2\%, and $22.4 \%$, respectively, compared with one-year, thee-year, and five-year survival rates of $72.2 \%, 69.5 \%$, and $55.3 \%$ respectively, in patients who did not need CRRT treatment $(P=0.002)$. The one-year, three-year, and five-year survival rates for patients who needed IABP treatment after surgery were 20.0\%, 20.0\%, and $20.0 \%$ respectively, in contrast to $65.4 \%, 62.1 \%$, and $54.5 \%$ in those patients who did not need IABP $(P<0.001)$.

\section{DISCUSSION}

Advanced NYHA functional classes in admission and the need for CRRT or IABP treatment were independent risk factors

Table 3. Univariate and multivariate analysis of risk factors of mid-term mortality.

\begin{tabular}{|c|c|c|c|c|c|}
\hline \multicolumn{2}{|c|}{ Variable } & $\mathbf{N}$ & 1-year survival (\%) & 3-year survival (\%) & 5-year survival (\%) \\
\hline \multicolumn{2}{|l|}{ Total } & 110 & $59.0 \pm 5$ & $52.0 \pm 6$ & $48.0 \pm 6$ \\
\hline \multirow{3}{*}{ NYHA } & $\|$ & 23 & 82.6 & 71.2 & 71.2 \\
\hline & III & 79 & 64.1 & 62.7 & 54.1 \\
\hline & IV & 8 & 0 & 0 & 0 \\
\hline \multirow{2}{*}{ CRRT } & No & 83 & 75.5 & 72.7 & 62.9 \\
\hline & Yes & 27 & 25.9 & 20.7 & 20.7 \\
\hline \multirow{2}{*}{ IABP } & No & 105 & 65.4 & 62.1 & 54.5 \\
\hline & Yes & 5 & 20.0 & 20.0 & 20.0 \\
\hline
\end{tabular}

CRRT=continuous renal replacement therapy; IABP=intra-aortic balloon pump; NYHA=New York Heart Association

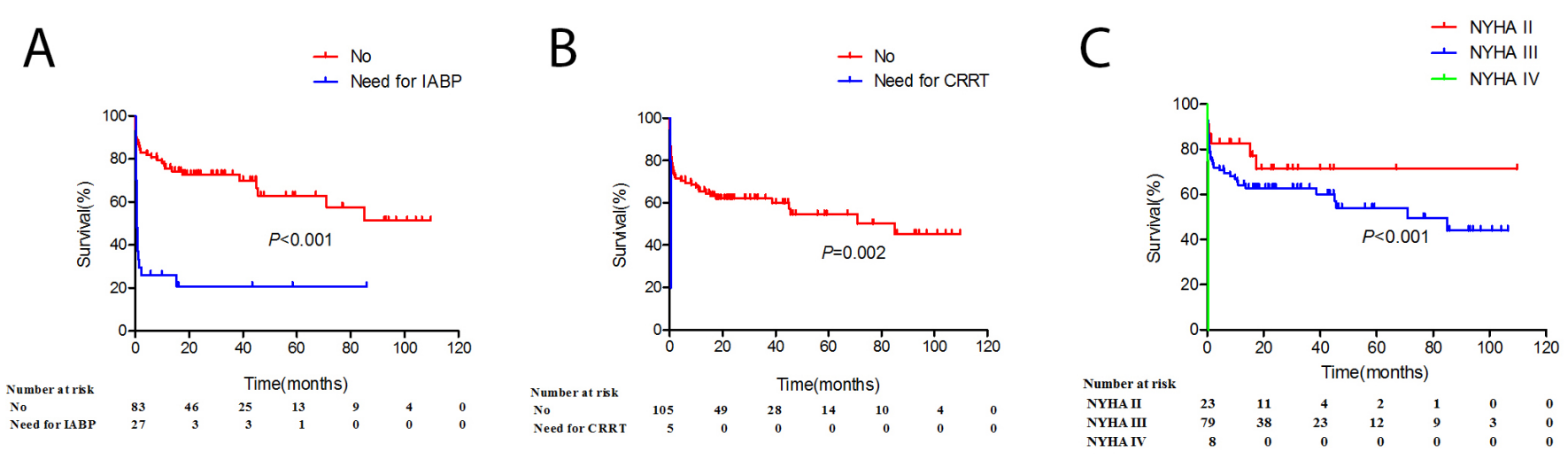

Fig. 1 - Survival curves A) according to the need for intra-aortic balloon pump (IABP) treatment, B) according to the need for continuous renal replacement therapy (CRRT) treatment, and C) according to New York Heart Association (NYHA) functional class. 
Table 4. Time-related survival rate for tricuspid valve replacement.

\begin{tabular}{|c|c|c|c|c|}
\hline \multirow[t]{2}{*}{ Characteristics } & \multicolumn{2}{|c|}{ Univariate } & \multicolumn{2}{|c|}{ Multivariate } \\
\hline & $\mathrm{HR}(95 \% \mathrm{Cl})$ & $P$-value & $\mathrm{HR}(95 \% \mathrm{Cl})$ & $P$-value \\
\hline Age, years & $1.000(0.980-1.020)$ & 1.000 & & \\
\hline Male, n & $0.768(0.435-1.358)$ & 0.365 & & \\
\hline Heart rate, bpm & $1.010(0.993-1.028)$ & 0.258 & & \\
\hline Systolic blood pressure, $\mathrm{mmHg}$ & $0.983(0.965-1.000)$ & 0.051 & & \\
\hline Diastolic blood pressure, mmHg & $0.989(0.965-1.014)$ & 0.393 & & \\
\hline Body mass index, $\mathrm{kg} / \mathrm{m}^{2}$ & $0.970(0.885-1.062)$ & 0.511 & & \\
\hline Isolated TVR, n & $0.915(0.502-1.669)$ & 0.772 & & \\
\hline Etiology for intervention, $\mathrm{n}$ & $0.885(0.658-1.189)$ & 0.418 & & \\
\hline Previous heart disease, $\mathrm{n}$ & $0.821(0.465-1.448)$ & 0.495 & & \\
\hline NYHA classification, n & $4.547(2.076-9.961)$ & $<0.001$ & $2.629(1.151-6.001)$ & 0.022 \\
\hline Coronary artery disease, $\mathrm{n}$ & $1.396(0.337-5.786)$ & 0.646 & & \\
\hline Hypertension, n & $0.776(0.279-2.164)$ & 0.628 & & \\
\hline Diabetes mellitus, $\mathrm{n}$ & $0.796(0.193-3.283)$ & 0.752 & & \\
\hline Atrial fibrillation, $\mathrm{n}$ & $1.013(0.574-1.788)$ & 0.966 & & \\
\hline Cardiopulmonary bypass time, min & $1.004(1.000-1.008)$ & 0.026 & $1.003(0.999-1.007)$ & 0.194 \\
\hline Aortic cross-clamping, $\mathrm{n}$ & $1.021(0.575-1.814)$ & 0.943 & & \\
\hline Prosthetic valve, $\mathrm{n}$ & $0.666(0.349-1.269)$ & 0.216 & & \\
\hline Hemoglobin, g/L & $0.992(0.981-1.002)$ & 0.122 & & \\
\hline Alanine aminotransferase, $U / L$ & $1.005(0.996-1.014)$ & 0.263 & & \\
\hline Bilirubin, umol/L & $1.035(1.020-1.049)$ & $<0.001$ & $1.017(0.999-1.035)$ & 0.060 \\
\hline Blood urea nitrogen, mmol/L & $1.039(1.003-1.076)$ & 0.031 & $1.041(0.987-1.097)$ & 0.138 \\
\hline Creatinine, $\mu \mathrm{mol} / \mathrm{L}$ & $1.007(1.001-1.013)$ & 0.032 & $1.004(0.995-1.013)$ & 0.360 \\
\hline $\mathrm{eGFR}, \mathrm{ml} / \mathrm{min} / 1.73 \mathrm{~m}^{2}$ & $0.996(0.989-1.003)$ & 0.238 & & \\
\hline Right atrial diameter, mm & $1.016(1.000-1.032)$ & 0.048 & $1.004(0.985-1.022)$ & 0.686 \\
\hline Right atrial length, mm & $1.010(0.995-1.025)$ & 0.206 & $1.010(0.986-1.034)$ & 0.421 \\
\hline Left atrium, mm & $0.986(0.967-1.006)$ & 0.183 & & \\
\hline Left ventricular ejection fraction $\leq 55 \%$ & $0.566(0.263-1.219)$ & 0.146 & & \\
\hline Left ventricular end-diastolic diameter, mm & $1.001(0.968-1.034)$ & 0.965 & & \\
\hline Right ventricle, mm & $1.028(1.002-1.056)$ & 0.037 & $0.983(0.941-1.026)$ & 0.434 \\
\hline Mitral regurgitation $\geq$ moderate, $\mathrm{n}$ & $1.166(0.523-2.601)$ & 0.707 & & \\
\hline Mitral stenosis $\geq$ moderate, $\mathrm{n}$ & $1.180(0.529-2.633)$ & 0.686 & & \\
\hline Tricuspid regurgitation $\geq$ severe, $\mathrm{n}$ & $0.896(0.480-1.671)$ & 0.729 & & \\
\hline RVSP, $\mathrm{mmHg}$ & $0.996(0.980-1.012)$ & 0.632 & & \\
\hline CRRT, n & $4.370(2.425-7.874)$ & $<0.001$ & $3.198(1.653-6.187)$ & 0.001 \\
\hline $\mathrm{ABP}, \mathrm{n}$ & $4.558(1.550-13.401)$ & 0.006 & $3.895(1.168-12.985)$ & 0.027 \\
\hline EuroSCORE II (\%) & $1.036(0.921-1.166)$ & 0.556 & & \\
\hline
\end{tabular}


strongly associated with increased mid-term mortality after TVR. The overall one-year, three-year, and five-year survival rates were $58 \% \pm 5 \%, 51 \% \pm 6 \%$, and $47 \% \pm 6 \%$, respectively. The results were similar to other published studies with reported five-year actuarial survival rates of $41.6 \%$ to $74 \% \%^{[3-11]}$.

The pathology of TR was attributed to damage of TV or to tricuspid annular dilation and ventricular enlargement, leading to improper TV leaflet coaptation ${ }^{[12]}$. Primary regurgitation results from lesions of the TV apparatus itself, such as endocarditis, rheumatic heart disease, or congenital malformation. More often, TR is functional and secondary to mitral regurgitation or stenosis, leading to increased left atrial pressure, secondary pulmonary hypertension, and finally functional TR. It was recommended that severe TR should be corrected at the time of the initial mitral valve surgery, with a class I recommendation suggested by two guidelines ${ }^{[13,14]}$. The American College of Cardiology guideline gives a class lla recommendation for TV annuloplasty in patients with tricuspid annular diameter $>40$ $\mathrm{mm}$ or $21 \mathrm{~mm} / \mathrm{m}^{2}$ diameter indexed to body surface area measured by $2 \mathrm{D}$ echocardiography or $>70 \mathrm{~mm}$ diameter measured by direct TV inspection during mitral valve surgery, even in the absence of functional TR (class IIa) ${ }^{[14]}$.

Organic TV disease often requires TVR surgery. Functional TR can usually be corrected with TV repair ${ }^{[15]}$. Nonring suture annuloplasty bicuspidalization (i.e., plication of the posterior leaflet) is often performed in rheumatic heart disease patients, whereas De Vega annuloplasty (i.e., plication of the annulus surrounding the anterior and posterior leaflets) is usually performed in patients with severe tricuspid annular dilation, remodeling the annulus by maintaining TV a more physiologic annulus ${ }^{[15]}$.

In correction of functionalTR, ring annuloplasty yields a better outcome compared to nonring repair ${ }^{[15,16]}$. Functional TR was previously thought to diminish after left-sided valve surgery ${ }^{[17]}$. Moderate-to-severe TR was an independent risk factor for adverse event and worse survival after mitral valve replacement ${ }^{[18]}$. In cases of less severe TR, left uncorrected at mitral valve surgery, $25 \%$ of the patients might worsen toward to severe TR across time and had worse outcome and survival ${ }^{[14]}$. So, aggressive prophylactic TV repair was suggested to be performed in patients undergoing mitral valve replacement regardless of TR severity. However, McCarthy et al. ${ }^{[16]}$ documented early failure in all types of TV annuloplasty repair in 14\% of 790 annuloplasty patients within one month, furthermore, more severe preoperative TR was significantly associated with higher late TR risk. Nakanishi et al. revealed residual TR significantly associated with worse surviva ${ }^{[19]}$. All efforts should be made to eliminate this residual functional TR after left-sided heart operations ${ }^{[20]}$.

Late TR after mitral valve replacement is often isolated and occurs in the absence of significant left heart disease ${ }^{[1]}$. However, in TR, isolated TV surgery is only recommended in symptomatic patients or patients who had progressed RV dilatation ${ }^{[21]}$. As a result, isolated TVR to correct TR is a difficult problem due to the late referral and manifestations of damaged RV function. RV failure is an outcome determinant in TV surgery. Seventy-two (65\%) patients in our study underwent isolated TVR surgery. Until now, data comparing tricuspid annuloplasty with TVR in functional TR after left-sided heart valve surgery has been scarce.
Mangoni et al..[22] supported the idea of performing TVR rather than repair because of the high risk of recurrence of significant TR after repair.

Evidence have accumulated that symptoms of RV failure, such as hepatomegaly and icterus ${ }^{[4]}$, anasarca ${ }^{[9]}$, ascites, and high preoperative bilirubin level[23], were associated with an increased mortality risk after TVR surgery. In patients who underwent cardiac surgery, the Model for End-stage Liver Disease and EuroSCORE were demonstrated to be useful in mortality prediction ${ }^{[24]}$. In 40 isolated TVR patients, a marginal association was demonstrated between logistic EuroSCORE I and mortality risk (HR 1.06, $P=0.001)^{[25]}$ We calculated the EuroSCORE II, it takes liver function into account and its calculation used clearance instead of serum creatinine, resulting in a more accurate measure of renal function compared to EuroSCORE I, however, no association was found with mortality in univariate or multivariate analysis. In Cox univariate analysis, we found out that higher preoperative bilirubin, blood urea nitrogen, and creatinine levels were significant mortality risk factors. However, this significance disappeared after adjustment of other risk factors.

It is recognized that not the surgery itself that is difficult, but rather the RV dysfunction after the restoration of competence to the insufficient TV that matters ${ }^{[1]}$. The restoration of valve competence via the correction of TR may lead to RV decompensation when RV cannot sustain the pressure and/or volume overload after the correction ${ }^{[26]}$.

Our current study demonstrated that patients ranked as advanced NYHA classes had significantly higher midterm mortality risk, a trend also observed in other published studies ${ }^{[6,27-29]}$. In our study, 87 (79.1\%) patients were in NYHA functional classes III/IV. The eight NYHA IV patients died immediately after operation. Patient selection is crucial for better surgical outcomes. Those NYHA IV patients should be modulated by optimizing medical support. No signs of cardiac functional improvement prior to surgery might serve as a contraindication of TVR. Recently, Hamandi et al. ${ }^{[30]}$ emphasized the importance of the periprocedural management of RV failure in TV surgery by proposing that the improvement of RV function can provide better outcomes. This can provide important guidance in the management of TV surgery patients.

Long-term TR leads to further RV dilation, TV annular dilation, and finally causes RV dysfunction ${ }^{[31,32]}$. Sharma et al. reported a $40 \%$ rate of worsening renal function in RV failure patients ${ }^{[33]}$. Patients with RV failure were also reported to be more predisposed to CRRT compared with non-RV failure patients ${ }^{[34]}$. Their further research revealed that renal deterioration was significantly associated with RV failure ${ }^{[35]}$. Furthermore, it was demonstrated to be a predictor of long-term mortality and morbidity outcomes in RV failure patients ${ }^{[36]}$. Five patients need IABP mechanical support as a result of low cardiac output and unstable hemodynamics. Two patients had moderate mitral stenosis before TVR and three patients had left ventricular ejection fraction less than $55 \%$ before surgery. Four patients who required IABP support died.

In the absence of gradient between the pulmonary valve and the RV outflow tract, the RVSP was assumed to be equivalent to the pulmonary artery systolic pressure ${ }^{[2]}$. In functional TR, 
elevated pulmonary artery systolic pressure is a major cause of $T R$, furthermore, TR progresses and regresses with the fluctuation of PASP ${ }^{[37]}$. There were studies correlating elevated pulmonary artery systolic pressure with increased early and long-term mortalities after $\operatorname{TVR}^{[6,23]}$. However, Mutlak et al. ${ }^{[38]}$ found no correlation of pulmonary artery systolic pressure with TR severity. In our study, we did not find any association between RVSP and mortality. Endocarditis has a high mortality in the immediate postoperative course. In endocarditis patients, five-year survival after TVR is $36.8 \%$. Four (16.7\%) of the 24 infective endocarditis patients were intravenous drug abusers, and they all died of infection. Most of endocarditis patients died of blood-borne disseminated lung abscess or other severe infections.

Until now, there was no clear superiority of one prosthesis over another, the decision should be individualized to the patient. The optimal choice of valve type in TVR is still controversial. Most studies have not demonstrated one valve type to outperform another in both early and late survival rates ${ }^{[4,8,11]}$. Our study also demonstrated that prosthesis type has no influence on survival. For the prosthesis choice, it was more often based on the surgeon's discretion and preference. Clinicians need to take time-related adverse events into consideration. In our institute, warfarin was initiated on postoperative day one or two in all stable non-bleeding patients, and warfarin dose was adjusted to maintain a target International Normalized Ratio of 1.8 to 2.5. Postoperative anticoagulation therapy in bioprosthetic replacement terminated after six months, whereas mechanical prostheses replacement required lifelong anticoagulation therapy. Bioprostheses have usually been advocated due to a lower demand of anticoagulation ${ }^{[4,39]}$. However, the degeneration of the bioprostheses and the higher reoperation rates are barriers for the application of this prosthesis type ${ }^{[2,4,40-42]}$; hence, the choice of a mechanical prosthesis has been preferred. There has also been a study demonstrating that no difference in reoperation rates was found between the prosthetic valves ${ }^{[8]}$.

However, with advanced surgical and transcatheter therapies, the transcatheter therapies with decreased risk of adverse events are applied to TV. As the management of valvular heart disease progresses, transcatheter edge-to-edge repair is reported to be performed in selected inoperable patients with severe $\mathrm{TR}^{[43]}$. Though difficult to anchor a transcatheter valve for TV, the Heterotopic Implantation of the Edwards-Sapien XT Transcatheter Valve in the Inferior VEna Cava for the Treatment of Severe Tricuspid Regurgitation - HOVER trial set out to explore the efficacy of caval valve implant in severe $\mathrm{TR}^{[44]}$, providing promising future for TR treatment.

Our current study supports the same idea, that poor cardiac function was the predominant cause of poor outcomes of TVR.

\section{Limitations}

First, this study was subject to the limitations that are inherent to a retrospective analysis of observational data. RV function was not systematically evaluated at either preoperative or postoperative time points. The quantitative echocardiography parameters reflecting RV systolic function, such as tricuspid annular plane systolic excursion and inferior vena cava size, were not estimated. Moreover, more precise estimates of RV function, such as 3D echocardiography or magnetic resonance imaging with excellent ability to quantitate RV volumes and ejection fraction, may help to identify those patients who will not benefit from TVR. Finally, this is a single center study with small sample size. Further cohort studies with large sample size are needed.

\section{CONCLUSION}

In TVR, advanced NYHA classes before operation and need for CRRT or IABP treatment after operation are mortality risk factors for mid-term outcomes.

\section{No financial support. \\ No conflict of interest.}

\section{Authors' roles \& responsibilities}

YC Substantial contributions to the conception or design of the work; or the acquisition, analysis, or interpretation of data for the work; drafting the work or revising it critically for important intellectual content; final approval of the version to be published

SM The acquisition of data for the work; final approval of the version to be published

KW The acquisition of data for the work; final approval of the version to be published

RF The acquisition of data for the work; final approval of the version to be published

YL Analysis, or interpretation of data for the work; final approval of the version to be published

SL The acquisition of data for the work; final approval of the version to be published

XZ Interpretation of data for the work; final approval of the version to be published

SY Interpretation of data for the work; final approval of the version to be published

YX Interpretation of data for the work; final approval of the version to be published

BT Substantial contributions to the conception or design of the work; revised it critically; final approval of the version to be published

ZW Substantial contributions to the conception or design of the work; revised it critically; final approval of the version to be published

\section{REFERENCES}

1. Shiran A, Sagie A. Tricuspid regurgitation in mitral valve disease incidence, prognostic implications, mechanism, and management. J Am Coll Cardiol. 2009;53(5):401-8. doi:10.1016/j.jacc.2008.09.048.

2. Rudski LG, Lai WW, Afilalo J, Hua L, Handschumacher MD, Chandrasekaran $\mathrm{K}$, et al. Guidelines for the echocardiographic assessment of the right heart in adults: a report from the American society of echocardiography endorsed by the European association of echocardiography, a registered branch of the European society of cardiology, and the Canadian society of 
echocardiography. J Am Soc Echocardiogr. 2010;23(7):685-713; quiz 786-8. doi:10.1016/j.echo.2010.05.010.

3. Guenther T, Noebauer C, Mazzitelli D, Busch R, Tassani-Prell P, Lange R. Tricuspid valve surgery: a thirty-year assessment of early and late outcome. Eur J Cardiothorac Surg. 2008;34(2):402-9; discussion 409. doi:10.1016/j. ejcts.2008.05.006.

4. Van Nooten GJ, Caes F, Taeymans Y, Van Belleghem Y, François K, De Bacquer D, et al. Tricuspid valve replacement: postoperative and longterm results. J Thorac Cardiovasc Surg. 1995;110(3):672-9. doi:10.1016/ S0022-5223(95)70098-6.

5. Carrier M, Hébert Y, Pellerin M, Bouchard D, Perrault LP, Cartier R, et al. Tricuspid valve replacement: an analysis of 25 years of experience at a single center. Ann Thorac Surg. 2003;75(1):47-50. doi:10.1016/s0003-4975(02)04162-0.

6. Filsoufi F, Anyanwu AC, Salzberg SP, FrankelT, Cohn LH, Adams DH. Long-term outcomes of tricuspid valve replacement in the current era. Ann Thorac Surg. 2005;80(3):845-50. doi:10.1016/j.athoracsur.2004.12.019.

7. Staab ME, Nishimura RA, Dearani JA. Isolated tricuspid valve surgery for severe tricuspid regurgitation following prior left heart valve surgery: analysis of outcome in 34 patients. J Heart Valve Dis. 1999;8(5):567-74.

8. Ratnatunga CP, Edwards MB, Dore CJ, Taylor KM. Tricuspid valve replacement: UK heart valve registry mid-term results comparing mechanical and biological prostheses. Ann Thorac Surg. 1998;66(6):1940-7. doi:10.1016/ s0003-4975(98)01183-7.

9. Mangoni AA, DiSalvo TG, Vlahakes GJ, Polanczyk CA, Fifer MA. Outcome following isolated tricuspid valve replacement. Eur J Cardiothorac Surg. 2001;19(1):68-73. doi:10.1016/s1010-7940(00)00598-4.

10. Scully HE, Armstrong CS. Tricuspid valve replacement. Fifteen years of experience with mechanical prostheses and bioprostheses. J Thorac Cardiovasc Surg. 1995;109(6):1035-41. doi:10.1016/S0022-5223(95)70185-0.

11. Glower DD, White WD, Smith LR, Young WG, Oldham HN, Wolfe WG, Lowe JE. In-hospital and long-term outcome after porcine tricuspid valve replacement. J Thorac Cardiovasc Surg. 1995;109(5):877-83; discussion 883-4. doi:10.1016/S0022-5223(95)70311-X.

12. Vismara R, Gelpi G, Prabhu S, Romitelli P, Troxler LG, Mangini A, et al. Transcatheter edge-to-edge treatment of functional tricuspid regurgitation in an ex vivo pulsatile heart model. J Am Coll Cardiol. 2016;68(10):1024-33. doi:10.1016/j.jacc.2016.06.022.

13. Baumgartner H, Falk V, Bax JJ, De Bonis M, Hamm C, Holm PJ, et al. 2017 ESC/EACTS guidelines for the management of valvular heart disease. Eur Heart J. 2017:38(36):2739-91. doi:10.1093/eurheartj/ehx391.

14. Nishimura RA, Otto CM, Bonow RO, Carabello BA, Erwin JP 3rd, Guyton RA, et al. 2014 AHA/ACC guideline for the management of patients with valvular heart disease: executive summary: a report of the American college of cardiology/American heart association task force on practice guidelines. Circulation. 2014;129(23):2440-92. Erratum in: Circulation. 2014;129(23):e650. doi:10.1161/CIR.0000000000000029.

15. Tang GH, David TE, Singh SK, Maganti MD, Armstrong S, Borger MA. Tricuspid valve repair with an annuloplasty ring results in improved long-term outcomes. Circulation. 2006;114(1 Suppl):1577-81. doi:10.1161/ CIRCULATIONAHA.105.001263.

16. McCarthy PM, Bhudia SK, Rajeswaran J, Hoercher KJ, Lytle BW, Cosgrove DM, et al. Tricuspid valve repair: durability and risk factors for failure. J Thorac Cardiovasc Surg. 2004;127(3):674-85. doi:10.1016/j.jtcvs.2003.11.019.

17. Duran CM, Pomar JL, Colman T, Figueroa A, Revuelta JM, Ubago JL. Is tricuspid valve repair necessary? J Thorac Cardiovasc Surg. 1980;80(6):84960. doi:10.1016/S0022-5223(19)37691-3.

18. Ruel M, Rubens FD, Masters RG, Pipe AL, Bédard P, Mesana TG. Late incidence and predictors of persistent or recurrent heart failure in patients with mitral prosthetic valves. J Thorac Cardiovasc Surg. 2004;128(2):278-83. doi:10.1016/j. jtcvs.2003.11.048.

19. Nakanishi K, Homma S, Han J, Takayama H, Colombo PC, Yuzefpolskaya $M$, et al. Prevalence, predictors, and prognostic value of residual tricuspid regurgitation in patients with left ventricular assist device. J Am Heart Assoc. 2018;7(13):e008813. doi:10.1161/JAHA.118.008813.

20. Teman NR, Huffman LC, Krajacic M, Pagani FD, Haft JW, Bolling SF. "Prophylactic" tricuspid repair for functional tricuspid regurgitation. Ann Thorac Surg. 2014;97(5):1520-4. doi:10.1016/j.athoracsur.2013.11.049.
21. Chang CC, Veen KM, Hahn RT, Bogers AJJC, Latib A, Oei FBS, et al. Uncertainties and challenges in surgical and transcatheter tricuspid valve therapy: a stateof-the-art expert review. Eur Heart J. 2019:ehz614. doi:10.1093/eurheartj/ ehz614.

22. Kim JB, Jung SH, Choo SJ, Chung CH, Lee JW. Surgical outcomes of severe tricuspid regurgitation: predictors of adverse clinical outcomes. Heart. 2013;99(3):181-7. doi:10.1136/heartjnl-2012-302856.

23. Baughman KL, Kallman CH, Yurchak PM, DaggettWM, Buckley MJ. Predictors of survival after tricuspid valve surgery. Am J Cardiol. 1984;54(1):137-41. doi:10.1016/0002-9149(84)90318-7.

24. Arif R, Seppelt P, Schwill S, Kojic D, Ghodsizad A, Ruhparwar A, et al. Predictive risk factors for patients with cirrhosis undergoing heart surgery. Ann Thorac Surg. 2012;94(6):1947-52. doi:10.1016/j.athoracsur.2012.06.057.

25. Redondo Palacios A, López Menéndez J, Miguelena Hycka J, Martín García M, Varela Barca L, Ferreiro Marzal A, et al. Which type of valve should we use in tricuspid position? Long-term comparison between mechanical and biological valves. J Cardiovasc Surg (Torino). 2017;58(5):739-46. doi:10.23736/ S0021-9509.16.09553-7.

26. Iscan ZH, Vural KM, Bahar I, Mavioglu L, Saritas A. What to expect after tricuspid valve replacement? Long-term results. Eur J Cardiothorac Surg. 2007;32(2):296-300. doi:10.1016/j.ejcts.2007.05.003.

27. Poveda JJ, Bernal JM, Matorras P, Hernando JP, Oliva MJ, Ochoteco A, et al. Tricuspid valve replacement in rheumatic disease: preoperative predictors of hospital mortality. J Heart Valve Dis. 1996;5(1):26-30.

28. Jugdutt BI, Fraser RS, Lee SJ, Rossall RE, Callaghan JC. Long-term survival after tricuspid valve replacement. Results with seven different prostheses. J Thorac Cardiovasc Surg. 1977;74(1):20-7.

29. Topilsky Y, Khanna AD, Oh JK, Nishimura RA, Enriquez-Sarano M, Jeon YB, Sundt TM, Schaff HV, Park SJ. Preoperative factors associated with adverse outcome after tricuspid valve replacement. Circulation. 2011;123(18):192939. doi:10.1161/CIRCULATIONAHA.110.991018.

30. Hamandi M, Smith RL, Ryan WH, Grayburn PA, Vasudevan A, George TJ, et al. Outcomes of isolated tricuspid valve surgery have improved in the modern era. Ann Thorac Surg. 2019;108(1):1 1-15. doi:10.1016/j.athoracsur.2019.03.004.

31. Sugimoto T, Okada M, Ozaki N, Hatakeyama T, Kawahira T. Long-term evaluation of treatment for functional tricuspid regurgitation with regurgitant volume: characteristic differences based on primary cardiac lesion. JThorac Cardiovasc Surg. 1999;117(3):463-71. doi:10.1016/s0022-5223(99)70325-9.

32. Sagie A, Schwammenthal E, Padial LR, Vazquez de Prada JA, Weyman AE, Levine RA. Determinants of functional tricuspid regurgitation in incomplete tricuspid valve closure: Doppler color flow study of 109 patients. J Am Coll Cardiol. 1994;24(2):446-53. doi:10.1016/0735-1097(94)90302-6.

33. Sharma K, Hill T, Grams M, Daya NR, Hays AG, Fine D, et al. Outcomes and worsening renal function in patients hospitalized with heart failure with preserved ejection fraction. Am J Cardiol. 2015;1 16(10):1534-40. doi:10.1016/j. amjcard.2015.08.019.

34. Bellavia D, lacovoni A, Scardulla C, Moja L, Pilato M, Kushwaha SS, et al. Prediction of right ventricular failure after ventricular assist device implant: systematic review and meta-analysis of observational studies. Eur J Heart Fail. 2017;19(7):926-946. doi:10.1002/ejhf.733.

35. Mukherjee M, Sharma K, Madrazo JA, Tedford RJ, Russell SD, Hays AG. Right-sided cardiac dysfunction in heart failure with preserved ejection fraction and worsening renal function. Am J Cardiol. 2017;120(2):274-278. doi:10.1016/j.amjcard.2017.04.019.

36. Rusinaru D, Buiciuc O, Houpe D, Tribouilloy C. Renal function and long-term survival after hospital discharge in heart failure with preserved ejection fraction. Int J Cardiol. 2011;147(2):278-82. doi:10.1016/j.ijcard.2009.09.529.

37. Medvedofsky D, Aronson D, Gomberg-Maitland M, Thomeas V, Rich S, Spencer K, et al. Tricuspid regurgitation progression and regression in pulmonary arterial hypertension: implications for right ventricular and tricuspid valve apparatus geometry and patients outcome. Eur Heart J Cardiovasc Imaging. 2017;18(1):86-94. doi:10.1093/ehjci/jew010.

38. Mutlak D, Aronson D, Lessick J, Reisner SA, Dabbah S, Agmon Y. Functional tricuspid regurgitation in patients with pulmonary hypertension: is pulmonary artery pressure the only determinant of regurgitation severity? Chest. 2009:135(1):115-21. doi:10.1378/chest.08-0277.

39. Nakano K, Eishi K, Kosakai Y, Isobe F, Sasako Y, Nagata S, et al. Ten-year 
experience with the Carpentier-Edwards pericardial xenograft in the tricuspid position. JThorac Cardiovasc Surg. 1996;1 11 (3):605-12. doi:10.1016/s00225223(96)70312-4.

40. Wiedemann D, Rupprechter V, Mascherbauer J, Kammerlander A, Mora B, Dimitrov K, et al. Tricuspid valve replacement: results of an orphan procedure - which is the best prosthesis? J Cardiovasc Surg (Torino). 2018;59(4):626-32. doi:10.23736/S0021-9509.18.10392-2.

41. Nakano K, Ishibashi-Ueda H, Kobayashi J, Sasako Y, Yagihara T. Tricuspid valve replacement with bioprostheses: long-term results and causes of valve dysfunction. Ann Thorac Surg. 2001;71(1):105-9. doi:10.1016/s00034975(00)02149-4.

42. Guerra F, Bortolotti U, Thiene G, Milano A, Mazzucco A, Talenti E, et al. Long- term performance of the Hancock porcine bioprosthesis in the tricuspid position. A review of forty-five patients with fourteen-year follow-up. JThorac Cardiovasc Surg. 1990;99(5):838-45. doi:10.1016/S0022-5223(19)36898-9.

43. Braun D, Orban M, Orban M, Hagl C, Massberg S, Nabauer M, et al. Transcatheter edge-to-edge repair for severe tricuspid regurgitation using the triple-orifice technique versus the bicuspidalization technique. JACC Cardiovasc Interv. 2018;11(17):1790-2. doi:10.1016/j.jcin.2018.05.049.

44. O'Neill BP, Wheatley G, Bashir R, Edmundowicz D, O'Murchu B, O'Neill WW, et al. Study design and rationale of the heterotopic implantation of the Edwards-Sapien XT transcatheter valve in the inferior VEna cava for the treatment of severe tricuspid regurgitation (HOVER) trial. Catheter Cardiovasc Interv. 2016;88(2):287-93. doi:10.1002/ccd.26530. 